\title{
Erratum to: A Rapid, Manual Method to Map Coronal-Loop Structures of an Active Region Using Cubic Bézier Curves and Its Applications to Misalignment Angle Analysis
}

\section{G. Allen Gary · Qiang Hu · Jong Kwan Lee}

Published online: 3 October 2013

(C) Springer Science+Business Media Dordrecht 2013

\section{Erratum to: Solar Phys}

\section{DOI 10.1007/s11207-013-0359-8}

We regret that Equation (6) for the tangent vector is incorrect. The equation should be

$$
\frac{\partial \mathbf{f}(u)}{\partial u}=\sum_{i=0}^{n-1} n\left[\mathbf{P}_{i+2}-\mathbf{P}_{i+1}\right] \beta_{n-1, i}(u) .
$$

The online version of the original article can be found under doi:10.1007/s11207-013-0359-8.

G.A. Gary $(\bowtie) \cdot$ Q. Hu

Center of Space Plasma and Aeronomic Research, The University of Alabama in Huntsville,

Huntsville, AL 35899, USA

e-mail: gag0002@uah.edu

Q. Hu

e-mail: qh0001@uah.edu

J.K. Lee

Department of Computer Science, Bowling Green State University, Bowling Green, OH 43403, USA e-mail: leej@bgsu.edu 